the low $\mathrm{pH}$ to inhibit production of toxin. In some fruits (for example, tomatoes) survival of aerobic spore bearers and yeasts may alter the $\mathrm{pH}$ and allow growth of $C$ botulinum spores, but this will be recognised by the container being blown. Salami and other dry fermented sausages are preserved by adding salt and nitrate and allowing ripening and drying to reduce the $\mathrm{pH}$ to $<5 \cdot 0$. An extensive review of the traditional methods of preserving foods observes that commercial products have an excellent safety record. ${ }^{4}$

The increasing use of modified atmosphere packaging and the dependence on refrigeration to extend the shelf life of raw meat, fresh fish, and several processed products without preservatives has stimulated interest in the risk of botulism from these products.

A modified atmosphere package is one in which a food product is stored in something other than air and includes vacuum packaging. ${ }^{5}$ This may result in an environment conducive to the growth of anaerobes, which, combined with the ability of non-proteolytic strains to grow at refrigeration temperature, has led to concern that toxin may be produced before spoilage is obvious to the consumer. ${ }^{6}$ Experimental studies have shown that the time taken for production of toxin varies with the atmosphere and the food. Efforts to quantify safe storage conditions for both raw meat and fish in modified atmospheres have been undertaken and predictive models devised..$^{78}$ Foods in modified atmosphere packaging have been available for several years in Europe and no cases of botulism have yet been attributed to their consumption. The possibility that ambient temperatures may be too high to inhibit toxin production, however, has led to calls for additional safety controls, including low dose irradiation, coinoculation with lactic acid bacilli, and heat treatment after packing.

Coleslaw prepared from shredded cabbage kept in modified atmosphere packaging has been associated with four cases of botulism, and subsequent inoculation studies showed that toxin could be detected within four days in the shredded cabbage. ${ }^{9}$ Toxin developed in mushrooms stored in sealed containers artificially contaminated with $C$ botulinum spores but was not produced if sufficient oxygen was present in the package. ${ }^{10}$ The Food and Drug Administration has advised that mushroom packaging should be pierced with air holes to prevent botulinum toxin forming. Similar measures with the packaging of all fresh vegetables would seem sensible.
The consumer demand for convenience foods with minimal or no preservative has led to the development of refrigerated processed foods with extended durability, and guidelines for studies to evaluate the risk of botulism in these products have been promoted. ${ }^{11}$ Workers studying the survival of $C$ botulinum in 11 such processed foods concluded that storing the product at or below $3.3^{\circ} \mathrm{C}$ was the single most important safety factor but questioned whether under retail and housekeeping conditions this was achievable. ${ }^{12}$ They also observed that recommended heating times for these foods before consumption could not be relied upon to inactivate botulinum toxin completely.

The application of hazard analysis of critical control points, a method of food hygiene risk assessment, to the production of refrigerated processed foods with extended durability and adequate labelling to distinguish them from apparently similar but more stable products are essential. ${ }^{13}$ The development of reliable, consumer friendly time-temperature indicators for refrigerated processed foods with extended durability and fresh foods in modified atmosphere packaging would do much to ensure customer confidence in these products. ${ }^{14}$ Foodborne botulism is a preventable illness.

Director,

D N/HUTCHINSON

Public Health Laboratory,

Royal Preston Hospital,

PrestonPR2 4HG

1 Critchley EMR, Mitchell JD. Human botulism. Br $\mathcal{F}$ Hosp Med 1990;43:290-2.

2 Critchley EMR, Hayes PJ, Isaacs PET. Outbreak of botulism in north west England and Wales, June 1989. Lancet 1989;ii:849-53.

3 St Louis ME, Peck SHS, Bowering D, Mogan GB, Blatherwick J, Baneriee S, et al. Botulism from chopped garlic: delayed recognition of a major outbreak. Ann Intern Med 1988;108:363-8.

4 Hauschild AHW. Clostridium botulinum. In: Doyle MP, ed. Foodborme bacterial pathogens. New York: Marcel Dekker, 1989:111-89.

5 Farber JM. Microbiological aspects of modified-atmosphere packaging technology-a review. fournal of Food Protection 1991;54:58-70.

6 Stammen K, Gerdes D, Caporaseo F. Modified atmosphere packaging of seafood. Food Science and Nutrition 1990;29:301-31.

Lambert AD, Smith JP, Dodds KL. Shelf life extension and microbiological safety of fresh meat a review. Food Microbiology 1991;8:267-97.

8 Baker DA, Genigeorgis C. Predicting the safe storage of fresh fish under modified atmospheres with respect to Clostridium botulinum toxigenesis by modelling length of the lag phase of growth Journal of Food Protection 1990;53:131-40.

9 Solomon HM, Kautter DA, Lilly T. Outgrowth of Clostridium botulinum in shredded cabbage at room temperature foumal of Food Protection 1990;53: 831-3.

10 Sugiyama H, Rutledge KS. Failure of Clostridium botulinum to grow in fresh mushroom packaged in plastic film overwraps with holes. Joumal of Food Protection 1978;41:348-50.

11 Doyle MP. Evaluating the potential risk from extended-shelf-life refrigerated foods by Clostridium botulinum inoculation studies. Food Technology 1991;45(4):154-6.

12 Notermans S, Dufrenne J, Lund BM. Botulism risk of refrigerated, processed foods of extended durability. Fournal of Food Protection 1990;53:1020-4.

13 Adams CE. Applying HACCP to sous vide products. Food Technology 1991;45:148-51.

14 Taoukis PS, Fu B, Labuza TP. Time-temperature indicators. Food Technology 1991;45:70-82

\title{
Cytokines and cancer
}

\section{Clinical trials and experimental studies are unravelling their paradoxes}

The cytokines, which include the interferons, tumour necrosis factor, and the interleukins, are a burgeoning and diverse family of peptide cell regulators. The availability of natural and recombinant cytokines has led to their use as antitumour agents and in limiting the myelosuppressive effects of cytotoxic chemotherapy. Their antitumour effects may be direct or indirect, disrupting the blood supply of tumours or stimulating immunological responses against tumours. They may also have other roles in the treatment of cancer, functioning as radiosensitisers, radioprotectors, and modulators of oncogene expression. Within the malignant process cytokine and cytokine receptors are disregulated, and cytokine produced by tumours may contribute to the pathophysiology of cancer.
The interferons are effective treatments of malignancy. In the chronic phase of chronic myeloid leukaemia treatment with interferon alfa has produced haematological remissions in up to $70 \%$ of patients and occasional reversions to a normal chromosomal state. Peripheral blood responses are reported in $80 \%$ of patients with hairy cell leukaemia. ${ }^{2}$ Responses to interferon alfa are also reported in patients with Kaposi's sarcoma (30\%), myeloma (10-20\%), carcinoid tumours $(40 \%)$, renal cell carcinoma $(5-20 \%)$, lymphoproliferative disorders (20-40\%), essential thrombocythaemia, and minimal residual disease after treatment for ovarian cancer. ${ }^{3}$ The possible synergy of interferon alfa with chemotherapy has been investigated in colorectal cancer with fluorouracil, ${ }^{4}$ in non-small cell lung cancer with cisplatin, ${ }^{5}$ and in melanoma 
with dacarbazine, with encouraging results. ${ }^{6}$ The median duration of response is usually short-for example, eight months in patients with renal cell carcinoma who initially respond completely. Side effects at a dosage of 3 megaunits thrice weekly are usually confined to flu-like symptoms. Whether response rates increase with higher dosages is contentious and unproved.

The roles of interferon beta and interferon gamma in cancer treatment remain uncertain. In renal cell cancer the response rate with interferon beta was $20 \% .^{8}$ In epithelial ovarian cancer systemic interferon gamma produced a $36 \%$ response rate, ${ }^{9}$ and in patients with minimal disease intraperitoneal treatment produced a $23 \%$ response rate. ${ }^{10}$ Intrapleural treatment with recombinant interferon gamma was also effective in a small study in early stage mesothelioma. ${ }^{11}$ The possibility of maintenance treatment with interferon to limit the progression of minimal disease has been explored in patients with myeloma and small cell lung cancer. ${ }^{12}$

In contrast with the response rates associated with the interferons, response rates of less than $5 \%$ with significant toxicities have been reported in phase I and II trials of systemic recombinant tumour necrosis factor. ${ }^{13}$ Tumour necrosis factor given intraperitoneally may have a role in the palliative treatment of intractable ascites in patients with ovarian cancer but does not have an appreciable antitumour effect. ${ }^{14}$ These findings of limited effect in patients contrast with those in animal cancer models, where tumour necrosis factor has greater efficacy. This may be due to the lower immunogenicity of human tumours and the great toxicity of high dosages of tumour necrosis factor in humans as compared with mice. ${ }^{15}$ Hopes have diminished that tumour necrosis factor alone will be a useful systemic antitumour agent, but its synergy with other cytokines and cytotoxic agents requires investigation.

The initial investigation of adoptive immunotherapy with interleukin 2 and lymphokine activated killer cells showed antitumour effects in solid tumours unresponsive to conventional treatment. Renal cell carcinoma and malignant melanoma responded particularly well. ${ }^{16}$ Treatment was associated with profound toxicity, mainly due to a vascular leak syndrome whose manifestations include pulmonary and cerebral oedema. Later studies, however, have failed to confirm the initial high response rates of $40-60 \%$, and in a recent report of five clinical trials of 350 patients with renal cell cancer only $15 \%$ responded. Some of these patients experienced long lasting responses, which may be the true advantage of treatment with interleukin 2 as compared with conventional treatment. ${ }^{17}$ The true response rate in melanoma is probably also lower than earlier reports suggested. ${ }^{18}$

Infusing interleukin 2 without lymphokine activated killer cells is probably just as effective as giving bolus doses of these agents and may be less toxic. ${ }^{17}$ Another approach is to inject lymphokine activated killer cells into the tumour during systemic treatment with interleukin 2. This led to the regression of gliomas in six of 23 patients. ${ }^{19}$

Lymphoid cells isolated from tumours incubated with interleukin 2 in vitro specifically localise to tumour sites when reinfused. One study has reported a $55 \%$ response rate in selected patients with malignant melanoma. ${ }^{20}$ Investigations of the feasibility of treatment with lymphoid cells isolated from tumours have also led to the first description of gene therapy in humans, by showing retrovirus-transfected lymphoid cells isolated from tumours localising to tumour sites after systemic administration. ${ }^{21}$ As with tumour necrosis factor, there may be synergy with other cytokines, and this is being investigated. ${ }^{22}$ Although nearly 2000 patients have been treated with adoptive immunotherapy, the use of interleukin 2 in cancer treatment remains controversial.
Cytokines have a role in the pathophysiology of cancer. The loss of normal responsiveness to the regulatory effects of transforming growth factor $\mathbf{B}$ and interferon may result in uncontrolled tumour growth..$^{23}$ Cytokines have been implicated as autocrine and paracrine growth factors: interleukin 1 in acute myeloid leukaemia, tumour necrosis factor in chronic lymphocytic leukaemia, interleukin 6 in myeloma, and macrophage colony stimulating factor in epithelial ovarian cancer. Cytokines may also contribute to metastasis by promoting angiogenesis, stimulating bone resorption, enhancing tumour cell adhesion, and inducing proteolytic enzymes. ${ }^{24}$ Experimental studies have shown that giving tumour necrosis factor and interleukin 1 promotes metastases, and cell lines transfected with the human tumour necrosis factor gene had greater metastatic potential than cells that did not produce tumour necrosis factor. ${ }^{25} 26$ These experimental observations may be relevant to human cancers; in epithelial ovarian cancers tumour necrosis factor may contribute to spread within the peritoneal cavity. ${ }^{27}$

Cytokines may contribute to paraneoplastic phenomena. Inappropriate production of tumour necrosis factor may cause anaemia in hairy cell leukaemia, B symptoms in lymphoma, and the syndrome of fever, weight loss, leucocytosis, and hypercalcaemia in patients with cancer of the head and neck. ${ }^{24}$ Interleukin 1 has been implicated in hypercalcaemia in patients with squamous cell cancers. ${ }^{28}$ Inappropriate production of tumour necrosis factor, interleukin 1 , and interferon gamma may contribute to malignant cachexia. ${ }^{29}$

Cytokines pose paradoxes that need unravelling in clinical trials and experimental studies. A better understanding of their roles in the pathophysiology of cancer will have important implications for treatment.

SALEEM MALIK Consultant Medical Oncologis

Ontario Cancer Research and Treatment Foundation,

Thunder Bay Regional Cancer Center,

Thunder Bay, Ontario,

Canada P7B Y 1

JONATHAN WAXMAN Reader in Oncology

Department of Clinical Oncology,

Royal Postgraduate Medical School

Hammersmith Hospital,

London W12 0NN

1 Talpaz M, Kurzrock R, Kantarjian H, Gutterman J. Therapy of chronic myelogenous leukaemi with interferons. Cancer Surv 1989;8:793-8.

2 Queseda JR, Itri L, Gutterman JU, Alpha interferon in hairy cell leukaemia. A five year follow up in 100 patients. F Interferon Res 1988;6:678-85.

Kelly S, Malik STA, Balkwill F. Cytokines in cancer therapy. In: Waring M, Ponder B, eds. The science of cancer treatment. England: MTP Press, 1990:127-60. (Cancer and biology, series B )

4 Wadler S, Lambersky B, Atkins M, Kirkwood J, Petrelli N. Phase II trial of fluorouracil and recombinant interferon alpha-2a in patients with advanced colorectal carcinoma. An eastern cooperative oncology study. $\mathcal{F}$ Clin Oncol 1991;9:1806-10.

5 Bowman A, Fergusson RJ, Allan SG, Stewart ME, Gregor A, Cornbleet MA, et al. Potentiation of cisplatin by alpha-interferon in advanced non-small cell lung cancer (NSCLC): a phase II study. cisplatin by alpha-interfe

6 Falkson CI, Falkson G, Falkson C. Improved results with the addition of interferon alpha-2b to dacarbazine in patients with malignant melanoma. $\mathcal{F}$ Clin Oncol 1991;9:1403-8.

Horoszewicz JS, Murphy GP. An assessment of the current use of human interferons in therapy of urological cancers. I Urol 1989;142:1173-9.

8 Triozzi P, Rinehart J. The role of IFN-beta in cancer therapy. Cancer Surv 1989;8:799-808.

Welander CE, Homesley HD, Reich SD, Levin EA. A phase II study of the efficacy of recombina interferon gamma in relapsing ovarian adenocarcinoma. Am $\mathcal{f}$ Clin Oncol 1988;11:465-9.

10 Pujade-Luraine E, Guastella JP, Colombo N, Namer N, Fumoleau P, Monnier A, et al. Intraperitoneal human recombinant interferon gamma as treatment of residual ovarian carcinoma at second look laparotomy. Proceedings of the American Society of Clinical Oncology 1991;10:192. (Abstract 642.)

11 Boutin C, Viallat JR, Van Zandwijk N, Douillard JT, Paillard JC, Geurin JC, et al. Activity of intrapleural recombinant gamma-interferon in malignant mesothelioma. Cancer 1991;67. 2033-7.

12 Mandelli F, Avvisati G, Amadoro S, Boccadoro M, Gernone A, Lauta VM, et al. Maintenance treatment with recombinant interferon alfa- $2 \mathrm{~b}$ in patients with multiple myeloma responding to treatment with induction chemotherapy. $N$ Engl f Med 1990;322:1430-4

13 Jones AL, Selby P. Tumour necrosis factor: clinical relevance. Cancer Surv 1989;8:817-36

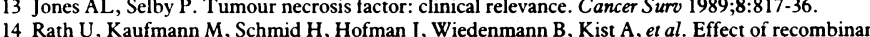
human tumour necrosis factor alpha on malignant ascites. Eur $\mathcal{F}$ Cancer 1991;27:121-5. 
15 Malik STA, Balkwill FR. The antiproliferative and antitumour actions of TNF in vitro and in vivo. $T N F$ : structure, function and mechanisms of action. New York: Marcel Dekker, 1991:239-68.

16 Rosenberg SA, Lotze MT, Leitman S, Ettinghausen SE, Matory YL, Skibber JM, et al. Observations on the systemic administration of autologous lymphokine-activated killer cells and recombinant interleukin 2 to patients with metastic cancer. N Engl J Med 1985;313:1485-92. 17 Palmer PA, Vinke J, Evers P, Pourreau C Oskam R, Roest G, et al. A review of patients treated by cont kine activated killer cells for the treatment of advanced renal cell carcinoma. Eur 7 Cancer (in

8 Bar MH, Snozl M, Atkins MB, Ciobanu N, Micetich KC, Boldt DH, et al. Metastatic melanoma treated with combined bolus and continuous infusion interleukin-2 and lymphokine activated killer cells. I Clin Oncol 1990;8:1138-47.

19 Yoshida S, Tanaka R, Takai N, Ono K. Local administration of autologous lymphokine-activated killer cells and recombinant interleukin 2 to patients with malignant brain tumours. Cancer Res 1988;48:5011-6.

20 Rosenberg SA, Packard BS, Aebersold PM, Solomon D, Topalian SL, Toy ST, et al. Use of tumour-infiltrating lymphocytes and interleukin-2 in the immunotherapy of patients with metastatic melanoma. $N$ Engl f Med 1988;319:1676-80.

21 Rosenberg SA, Aebersold P, Cornetta K, Kasid A, Morgan RA, Moen R, et al. Gene transfer into humans-immunotherapy of melanoma using tumour-infiltrating lymphocytes modified by retroviral gene transduction. $N$ Engl f Med 1990;323:570-8.

22 Thomas H, Barton C, Saini A, Dalgleish A, Waxman J. Sequential interleukin-2 and alph interferon for renal cell carcinoma and melanoma. Eur $\mathcal{F}$ Cancer (in press).

23 Roberts AB, Kim S, Sporn MB. Is there a common pathway mediating growth inhibition by TGFbeta and the retinoblastoma gene product? Cancer Cells 1991;3:19-21.

24 Malik STA. Tumour necrosis factor: roles in cancer pathophysiology. Seminars in Cancer Biolog $1992 ; 3: 27-33$

25 Malik STA, Griffin DB, Fiers W, Balkwill FR. Paradoxical effects of tumor necrosis factor in experimental ovarian cancer. Int $\mathcal{f}$ Cancer 1989;44:918-5.

26 Malik STA, Naylor MS, Oliff A, Balkwill FR. Cells secreting tumour necrosis factor show enhanced metastasis in nude mice. Eur f Cancer 1990;26:1031-4.

27 Naylor MS, Malik STA, Jobling T, Stamp G, Balkwill F. Demonstration of mRNA for tumou necrosis factor in human ovarian cancer by in situ hybridisation. Eur $\mathcal{f}$ Cancer 1990;26:1027-30. 28 Sato K, Fujii Y, Ono M, Nomura H, Shizume K. Production of interleukin la-like factor by a squamous cell carcinoma of the thyroid (T3M-5) derived from a patient with hypercalcaemia and leucocytosis. Cancer Res 1987;47:6474-80.

29 Lowry SF. Cancer cachexia revisited: old problems and new perspectives. Eur $\mathcal{f}$ Cancer 1991;27:1-3.

\section{Screening, ethics, and the law}

\section{Ensure that subjects know what's going on}

In traditional medical practice patients ask doctors for advice and treatment for their complaints. The doctor's duty is to do only that for which the patient has given informed consent and to provide care conforming to the standards set by a reasonable body of medical opinion. The patient usually understands, and is often reminded, that diagnostic procedures and treatment may have adverse effects. Screening for asymptomatic or occult disease differs from this: the contact is initiated by health care providers, who seek out people who believe themselves to be well with an offer to optimise their future health. By offering to screen, however, the doctor assumes the same duty of care as if the patient had initiated the contact.

Screening programmes should be regarded as research procedures until their value and safety are firmly established. Review by a local research ethics committee before their introduction is therefore mandatory. ${ }^{1}$ The committee must first consider the proposal in the light of the long established criteria for screening tests and programmes laid down by Cochrane and Holland, ${ }^{2}$ and Wilson and Jungner. ${ }^{3}$ These criteria require that the condition that is to be screened for should be sufficiently important to make screening worthwhile, that its natural history should be known, and that treatment at the presymptomatic stage should favourably influence outcome. Anyone invited to undergo a screening test is entitled to assume that these requirements have been met.

When a proposal is made to introduce a new screening test the ethics committee may be confronted with an ethical dilemma. To determine the natural history of a condition and to evaluate the potential benefits of early treatment it may be necessary to gather a sample of people whose condition is at the presymptomatic stage. To do this, however, may require the testing or examining of a large population of apparently healthy people. ${ }^{4}$ Clearly, if ethics committees insist that all Wilson and Jungner's criteria are fulfilled before permitting research programmes to start, the necessary data will never be obtained. In these circumstances ethics committees should encourage researchers to gather the necessary epidemiological data, but the temptation to intervene should be resisted, until the natural history of the condition has been clarified and the predictive value of the investigations is known. To give informed consent, therefore, subjects must understand that participation in the research programme will not benefit them, although the results may help others in the future.
Failure to obtain informed consent for a screening procedure is not only ethically unacceptable ${ }^{5}$ but also exposes the health authority to the risk of litigation. When assessing a proposed new screening programme ethics committees should not be content with assurances that subjects will receive a clear oral explanation. Only by insisting on a clear information sheet or leaflet and reading it carefully can they assess whether all questions will be honestly answered. Furthermore, the adverse psychological consequences of screening may be minimised if subjects understand precisely what the screening programme offers. ${ }^{6}$ Whoever obtains consent should note in the medical record what information has been given to the subject. The time taken to obtain genuinely informed consent must be included when calculating the cost of any screening programme, whether it is established practice or still at the research and development stage.

Failure to provide adequate information for the subject to give informed consent may not only result in an action for negligence but also lead to an action for trespass against the person. ${ }^{7}$ To give consent subjects must understand the nature of the screening process. They should be told what the test is for and - if known - its false positive and false negative rates. The consequences of a positive result must be explained. In some circumstances - for example, antenatal screening tests for congenital abnormality - these can be serious, ${ }^{8}$ entailing extensive investigations and perhaps culminating in the loss of a normal infant because of a false positive result or a complication of the diagnostic procedure.

A false negative result may delay diagnosis, and the subject must be warned that screening tests can never be perfect. For example, congenital deafness is easily missed in infancy because the screening test is difficult to do well. If parents are told that the child has "passed" they may dismiss any concerns they have about the child's hearing so that screening may delay rather than facilitate the diagnosis. ${ }^{9}$ Even more disturbing, in the context of antenatal screening, is the possibility that a false negative result may be followed by the birth of a severely handicapped child, with disastrous emotional and legal consequences.

A subject who has suffered unpleasant or hazardous procedures as a result of a screening test, or who was wrongly reassured by a false negative result, might bring a successful action if he or she could show that the nature and limitations of the screening process had not been adequately explained or 